\title{
A HISTÓRIA DE VIDA AGUÇADA PELOS BIOGRAFEMAS: UM RECORTE DA HISTÓRIA DE JUSAMARA SOUZA COM O CAMPO DA EDUCAÇÃO MUSICAL
}

\author{
The life story sharpened by bripgraphies: an \\ excerpt from Jusamara Souza's story with \\ the field of music education
}

\author{
La historia de la vida aguçada de \\ biografemas: un extracto de la historia de \\ Jusamara Souza en el campo de la educación \\ musical
}

DELMARY VASCONCELOS DE ABREU

Universidade de Brasília (UnB) delmaryabreu@gmail.com

\begin{abstract}
Resumo: Este artigo apresenta um recorte de uma pesquisa de pós-doutorado que teve como objeto de estudo a história de vida de Jusamara Souza com o campo da educação musical e seus desafios epistemológicos. Tomei como um dos objetivos da pesquisa: dar visibilidade às histórias de vida profissional de uma educadora musical que faz parte da história da educação musical no Brasil pelas suas compreensões sobre como o campo da educação musical vem se configurando. Tomei como pressupostos teóricos e metodológicos a sua história de vida, que permite construir a expressão biográfica de uma vida privada, e a sua passagem para uma vida social por meio da produção do conhecimento, entrelaçada com os efeitos do vivido. Seus feitos retratam o modo como ela foi se constituindo como uma das referências na área da educação musical brasileira.
\end{abstract}

Palavras-chave: Campo da educação musical. História de vida. Musicobiografia.

\begin{abstract}
This article presents an excerpt from a postdoctoral research that had as object of study the life story of Jusamara Souza with the field of music education and its epistemological challenges. I took as one of the objectives of the research: to give visibility to the histories of professional life, of a musical educator that is part of the history of music education in Brazil for its understandings about how the field of music education has been setting up. I took as theoretical and methodological approach the life story that allows the construction of the biographical expression of a private life and its passage to a social life by means of the production of knowledge, interlaced with the effects of the lived. Her achievements reflect the way she was becoming as one of the references in the area of Brazilian music education.
\end{abstract}

Keywords: Field of music education. Life's history. Musicbiography.

Resumen: Este artículo presenta un extracto de una investigación posdoctoral que tuvo como objeto de estudio la historia de la vida de Jusamara Souza en el campo de la educación musical y sus desafios epistemológicos. Tomé como uno de los objetivos de la investigación: dar visibilidad a las historias de la vida profesional de una educadora musical que hace parte de la historia de la educación musical de Brasil por su comprensión sobre cómo se ha venido configurando el campo de la educación musical. Tomé como presupuestos teóricos y metodológicos la historia de vida que permite construir la expresión biográfica de una vida privada, su paso a una vida social a través de la producción de conocimiento, entrelazado con los efectos de lo vivido. Sus obras retratan la forma como se fue constituyendo como una de las referencias en el área de la educación musical brasileña.

Palabras clave: Campo de la educación musical. Historia de vida. Musicobiografia. 


\section{INTRODUÇÃO}

Este texto foi elaborado no âmbito de uma pesquisa de pós-doutorado, realizada por mim no ano de 2018, na Universidade Federal de Pelotas (UFPel), sob a supervisão da professora doutora Maria Helena Menna Barreto Abrahão. Os estudos estiveram pautados nas obras do filósofo Paul Ricoeur, com destaque para as obras Tempo e Narrativa (2010) e O Si mesmo como um outro (2014).

Neste artigo, retomo de forma bastante sintética partes do texto elaborado para o projeto de pesquisa proposto para o estágio de pósdoutoramento, considerando, principalmente, os objetivos advindos da seguinte questão: $O$ que há de memorável nas trajetórias profissionais de educadores musicais brasileiros? Inolvidavelmente é tratar sobre como esses profissionais construíram e vêm construindo a área da educação musical no Brasil.

O percurso do reconhecimento de um campo investigativo, como foi o caso da educação musical no Brasil, percorre diferentes caminhos até chegar ao status de área. Mas tal reconhecimento é feito do trabalho exaustivo de autores comprometidos com uma área do conhecimento. Nos termos de Passeggi e Souza (2017), e parafraseando-os, é um movimento (auto)biográfico no Brasil com suas configurações no campo da educação musical. Também, como nos lembra Margarete Arroyo (2002, p. 18), "a trajetória da educação musical se faz e se fez através dos pensamentos e das realizações de educadores musicais e/ou pesquisadores".

Inquirir os fundamentos da pesquisa (auto)biográfica em educação musical, a partir dos estudos conduzidos sobre as histórias de vida de educadores musicais, tem, conforme Abreu (2016) e Abrahão (2016; 2018), a intencionalidade de interrogar os fundamentos da pesquisa (auto)biográfica em educação musical, com a finalidade de depreender principios epistemológicos, na tentativa de apontar possiveis contribuições na produção de conhecimento da área.

No início dos anos 1990, surgiram as produções dos doutores pioneiros da área, dos quais Alda Oliveira, Raimundo Martins e Vanda Freire fazem parte. Irene Tourinho, Jusamara Souza, Esther Beyer e Liane Hentschke também se juntam a esse corpo dos primeiros doutores da área. Segundo Oliveira (1995), “com as primeiras teses de mestrado e doutorado inaugurou-se uma nova fase de estudos científicos sobre os processos de formação de profissionais e sobre assuntos que interessam à resolução de problemas brasileiros" (Oliveira, 1995, p. 7). Data também deste periodo a criação da Associação Brasileira de Educação Musical (Abem), em 1991, capitaneada por Alda Oliveira, na época pesquisadora e docente da Universidade Federal da Bahia. 
Tomo como propósito dar a conhecer trajetórias singulares-universais de pesquisadores da área que, por terem participado e continuarem participando da construção da história da educação musical brasileira, vêm produzindo conhecimentos científicos. Desses, escolhi a pesquisadora Jusamara Souza, que faz parte dessa história como uma das fundadoras da Abem e que, juntamente com Alda Oliveira, no ano de 2017, foram homenageadas como sócias beneméritas da Associação pelo reconhecido trabalho empreendido ao longo dos últimos trinta anos na construção da educação musical no Brasil.

Acredito que, ao trazer as trajetórias profissionais de educadores musicais, professores e pesquisadores - meu objeto de estudo -, será possivel dizer que, nas "várias histórias da educação musical no Brasil" (Souza, 2014, p. 110), há um esforço a ser empreendido nos sentidos produzidos no campo da educação musical na tentativa de compreender, na história de vida profissional de educadores, professores e pesquisadores, a percepção da própria historicidade da área.

Pensando com o texto "Biografias", de José Saramago (2008), "todos os seres humanos deveriam deixar relatadas por escrito as suas vidas", porque, se assim não o fizerem, possiveis questionamentos sobre um mar de conhecimentos poderiam ser abertos - como, por exemplo, o que levam pesquisadores, autores a terem essa ou aquela visão. Assim, tomamos como objeto de estudo compreender na história de vida profissional dessa pesquisadora que trajetórias são essas que levaram à sua visão de educação musical.

A pesquisa em destaque caracteriza-se como um estudo que se ocupa com os aspectos músico-históricos, pedagógico-musicais e musicobiográficos, para que façam emergir na história de vida profissional dessa educadora musical brasileira uma compreensão do campo da educação musical na sua perspectiva. As aproximações epistemológicas das áreas de educação musical com a pesquisa (auto)biográfica são condições essenciais para que, como pesquisadora, possa contribuir com o fazer científico. Nessas aproximações, estão envolvidos os objetos de estudo que entrelaçam os problemas relacionados à relação do sujeito com a música sob os aspectos de apropriação e transmissão (Kraemer, 2000), evidenciando a subjetividade, o espaço, o tempo, as práticas e os saberes individuais e sociais.

No campo semântico da ação, a narrativa musico-biográfica pode ser compreendida, na prefiguração, com noções fundadas na vida (bio) com a música e no uso de instrumentos semióticos (grafias - estruturas e símbolos), derivando daí noções a serem estudadas, refiguradas e mais bem conceituadas no campo da educação musical. Nessa direção, a terminologia musicobiografia aproxima epistêmica e metodologicamente as áreas de educação musical e pesquisa (auto)biográfica (Abreu, 2018). 
Para nortear o objeto de estudo proposto, tomei como um dos objetivos da pesquisa dar visibilidade às histórias de vida profissional de uma educadora musical, que faz parte da história da educação musical no Brasil pelas suas compreensões sobre como o campo da educação musical vem se configurando. Convém salientar que os arquivos e textos são exclusivos, oriundos de fontes geradas, por mim, no processo de realização da pesquisa pós-doutoral.

\section{A HISTÓRIA DA PESQUISA E SEUS PROCEDIMENTOS METODOLÓGICOS}

Foi a partir do ano de 2007 que passei a conviver mais de perto com Jusamara Souza, pesquisadora e professora orientadora no Programa de Pós-Graduação em Música da Universidade Federal do Rio Grande do Sul (UFRGS), no qual realizei o meu processo de doutoramento em Educação Musical. Tal convívio culminou em sua participação na banca de minha defesa de doutorado em 2011. Ao lado de Jusamara Souza, esteve em minha banca a pesquisadora e supervisora do meu estágio pós-doutoral, Maria Helena Menna Barreto Abrahão. Sete anos depois, no ano de 2018, nos encontramos novamente em uma tríade narrativa.

Dentro de uma proposta de tríade, Delory-Momberger (2006, p. 361) considera que "as histórias contadas são faladas e questionadas no seio do grupo de três pessoas, triades que permitem sair da relação dual projetiva e favorecem a emergência da fala". E é nesse cenário que a construção da pesquisa se deu, qual seja: 1) registrando a obra da pesquisadora entrevistada em formato de biograma para que, no circuito da narratividade e no tempo da entrevista narrativa, as prefigurações e configurações fossem refiguradas no mundo do texto; 2) estudando com a supervisora do estágio pós-doutoral teorias que fundamentam a pesquisa, dentre elas a principal, que é a tese do Tempo e Narrativa, de Paul Ricoeur (2010); 3) refigurando no mundo do texto as compreensões moduladas pelo horizonte de aberturas advindas dos conhecimentos gerados na experiência da pesquisa. Foi, portanto, no circuito da narratividade que construímos a história da pesquisa.

Nos meandros de uma história narrada, além do narrador, outras personagens se personificam, entre elas, o supervisor e o próprio pesquisador. Portanto, produzir a história da pesquisa permite uma ampliação e uma transformação de experiências humanas que se comprometem, no circuito da narratividade, com a palavra dada em uma escuta atenta em que a narrativa do sujeito está em evidência para que se identifiquem e se organizem as estruturas cênicas (Abrahão, 2016, p. 265).

No trabalho realizado, considerei um espaço formabilité - aquele em que as narrativas realizam um trabalho de mediação, pois, como escreve DeloryMomberger: "É a narrativa que designa os papéis aos personagens de nossas 
vidas, que define posições e valores entre eles, [...] que polariza as linhas de nossos argumentos entre um começo e um fim e os atrai para sua conclusão" (Delory-Momberger, 2006, p. 361). A autora destaca que a história de vida "compõe uma totalidade significante em que cada acontecimento encontra seu lugar de acordo com sua contribuição à realização da história contada". Traz, também, a clareza de que "é a narrativa que faz de nós o próprio personagem de nossa vida, é ela, enfim, que dá uma história à nossa vida" (Delory-Momberger, 2006, p. 362).

As narrativas (auto)biográficas que compõem a história de vida profissional de Jusamara Souza foram construídas no circuito da narratividade por ocasião das oito entrevistas narrativas (EN) realizadas nos anos de 2018 e 2019.

As narrativas foram enriquecidas não só com fontes orais e documentais em formato de artigos, capítulos e livros organizados e prefaciados por Jusamara Souza, mas também com leituras do seu memorial acadêmico apresentado como um dos requisitos para o concurso de professora titular - além de teses e dissertações orientadas por ela e conversas com pessoas que se dispuseram a dar o seu depoimento. Isso contribuiu para compor a sua história de vida profissional, que estruturei seguindo o critério de valoração do biograma.

O biograma é, para Bolivar, Domingo e Fernandes (2001), uma forma inicial de análise de um relato de vida profissional mediante a elaboração de um mapa dessa trajetória com a cronologia dos acontecimentos, deixando uma terceira coluna para introduzir anotações de significados e valores que o entrevistado atribui aos acontecimentos. É um encadeamento do mundo vivido, adquirido nos mais diversos compromissos institucionais em ocupações e atividades formativas e de carreira (Bolivar; Domingo; Fernandes, 2001, p. 177-178).

Os episódios foram construídos com temas que emergiram das fontes orais e documentais dentro da tríplice mimese da "aventura (auto)biográfica", como esclarece Pineau (2012), que consiste em fazer da sua história de vida um modo de "exprimir-se, socializar-se e avaliar-se formativamente" (Pineau, 2012, p. 139).

Por acreditar e me embasar nos pressupostos teóricos e metodológicos das histórias de vida e sua grande representatividade para a área de Educação, decidi pesquisar a história de vida profissional de Jusamara Souza com a educação musical, pois [1] a expressão biográfica de uma vida privada, [2] a sua passagem a uma vida social pela produção do conhecimento, entrelaçada com [3] os efeitos do vivido, é que me lançam a essa triplice aventura (auto)biográfica. Disso, o que me interessa é a terceira aventura, isto é, os efeitos do vivido trazidos no momento da entrevista e que aclaram no processo analítico os seus feitos advindos das outras duas aventuras, retratando na sua vida profissional o modo como foi se 
construindo como uma das referências na área de educação musical, um projeto de vida com a educação musical brasileira construído na perspectiva da sociologia da vida cotidiana.

\section{BIOGRAFIZAÇÃO E PROJETO DE SI}

A arte de tecer um enredo se realiza, segundo Ricoeur (2010, tomo I), mediante três movimentos miméticos. O primeiro - Pré-figuração -, enraizado na pré-compreensão do mundo e da ação, nas fontes simbólicas, no caráter temporal e nas operações estruturantes. Nesse aspecto, a pesquisa (auto)biográfica não constrói conceitos, mas integra-se àqueles preestabelecidos pelo narrador. O segundo movimento - Configuração interpreta e compreende os fatos biográficos configurados em um enredo, em uma intriga apreendida no tempo humano quando na produção de sentido em forma de texto. O terceiro movimento - Refiguração - conclui o percurso narrado. Sendo assim, nos dois primeiros movimentos, ocorre o processo de biografização, isto é, a produção de sentidos na forma de texto. No terceiro movimento, encontra-se a recepção do texto, no movimento que o leitor faz diante do outro como um si mesmo e do si como um outro, produzindo uma identidade narrativa.

Compreendo, com os estudos de Passeggi, Abrahão e DeloryMomberger (2012), que "o trabalho de textualização exige que nos apropriemos de um gênero discursivo adequado à situação cultural de produção e recepção do texto", como fontes documentais e (auto)biográficas, entendendo que em todos eles "o trabalho de interpretação instala um círculo hermenêtico entre compreender (voltar-se para si em busca de sentido) e explicar (expressar o que compreendeu) num movimento que transita de um para o outro" (Passeggi; Abrahão; Delory-Momberger, 2012, p. 46). Será, portanto, nesse movimento textual enredado pelas narrativas (auto)biográficas e demais fontes documentais que uma dimensão da relação de Jusamara Souza com a área da educação musical será apresentada.

\section{O COTIDIANO COMO PERSPECTIVA PARA PESQUISAS EM EDUCAÇÃO MUSICAL}

Por meio de fontes documentais, produção bibliográfica e narrativa (auto)biográfica, Jusamara faz configurações de como foram seus dois primeiros anos no Brasil, após a conclusão do doutorado feito na Alemanha:

Em 1995, já como doutora, fui contemplada com uma bolsa de pesquisa do CNPq na modalidade de Recém-Doutora, para realizar atividades [durante 24 meses] na Universidade do Rio Grande do Sul [UFRGS]. [...] Em maio de 1997 fiz o concurso público para professor efetivo na UFRGS, focado na área de sociologia da educação musical. Em agosto de 1997, iniciei minha carreira como docente e pesquisadora da 
Universidade Federal do Rio Grande do Sul, [...], atuando com as disciplinas do campo da sociologia da educação musical (Souza, 2016, p. 9).

Como recém-doutora, o Conselho Nacional de Desenvolvimento Cientifico e Tecnológico (CNPq) concedeu-lhe uma bolsa para desenvolver a pesquisa "O cotidiano como perspectiva para a aula de música: concepção didática e exemplos práticos" (Souza, 2016, p. 9), bem como a possibilidade de registrar um grupo de pesquisa. Foi então que, em março de 1996, criou o seu grupo de pesquisa, que vem coordenando há mais 23 anos.

O Grupo de Pesquisa Educação Musical e Cotidiano - EMCO foi criado por mim em março de 1996 com a tarefa de levar adiante o projeto submetido ao $\mathrm{CNPq}$, intitulado "O cotidiano como perspectiva para a aula de música: concepção didática e exemplos práticos". O grupo é registrado no Diretório de Grupos de Pesquisa do CNPq e está vinculado ao Programa de Pós-Graduação em Música da UFRGS.

Deste o início considerei o grupo de pesquisa como um espaço de formação, no qual podíamos aprofundar os processos de análise pedagógica, metodológica e epistemológica de nossas práticas como professores de música. Com a minha entrada no Programa de PósGraduação, a partir de 1998, o grupo tornou-se também um espaço de estudar coletivamente autores que são referências para a linha de pesquisa, avaliar e discutir projetos de pesquisa, preparar publicações e organizar participações em congressos (Souza, 2018b).

Como descrito também em seu memorial acadêmico, o grupo de pesquisa foi instituído como um espaço de formação "no qual aprofundávamos os processos de análise pedagógica, metodológica e epistemológica de nossas práticas como professores" (Souza, 2016, p. 30). De fato, o grupo de pesquisa tornou-se mais um espaço destinado aos encontros de professores da rede de educação básica, licenciandos e pósgraduandos em Música da UFRGS. Essa foi, portanto, a pesquisa que a introduziu no cenário da educação musical brasileira como professora/pesquisadora e formadora de pesquisadores dentro de um campo implicado com a sociologia da educação musical e as teorias do cotidiano.

E junto com esse projeto de pesquisa, diretamente vinculado com a sociologia da vida cotidiana, percebi que aqui, no Brasil, não havia discussões nesse sentido, porque, afinal, para se falar em pesquisa em sociologia da educação musical, teria que se definir o que é a área e o que é fazer pesquisa na área de educação musical. Então, eu acho que o meu texto de 1996 [Souza, 1996a] acabou se tornando quase um clássico, porque nele juntei as duas coisas que são bem importantes. E, ao longo da minha carreira, com os cursos, 
com aulas, com os alunos da graduação, eu sempre tenho retomado esse texto que trata da epistemologia da área até em disciplinas específicas que temos aqui no Programa de Pós-Graduação em Música da UFRGS. Falo isso porque, talvez, ao longo do tempo, essa temática vai se desenvolver ainda mais, porém percebo que hoje ainda temos que tê-la como pauta de discussão, porque uma coisa está ligada a outra: a necessidade de tratar o estatuto epistemológico da área, a partir do que ela vem produzindo, e os aprofundamentos na maneira de se fazer pesquisa e de orientar com enfoque na sociologia da vida cotidiana (EN4, p. 7).

É evidente, na entrevista narrativa, o entusiasmo de Jusamara Souza com esse novo projeto de vida. Nele, um aprender a apropriar-se dos saberes constitutivos em um conjunto de relações com os outros e consigo mesma. Tanto que, na perspectiva da sociologia da educação musical, lança novos olhares sobre o vivido em contínuo processo de biografização com a pesquisa. Como consequência, a constituição de um grupo de pesquisa e o processo do vir a ser uma pesquisadora foi, para ela, fazer escolhas diante daquilo que acreditava e que poderia seguir continuamente ao longo de sua vida profissional:

Houve momentos que foram bem-sucedidos no sentido de reconhecimento dessa visão epistemológica da área, dessa presença da sociologia da educação musical no Brasil. Desse retorno, o que é palpável para mim foi o de ter seguido, continuamente, com esse projeto. Quando assumi a docência universitária na UFRGS, em 1997, propus, como parte integrante do meu estágio probatório, um projeto de pesquisa que dava continuidade àquele apresentado para $\mathrm{o}$ CNPq, em 1995, com a mesma visão epistemológica. Hoje vejo que aqueles projetos, de 1995 e 1997, não foram destinados apenas para aqueles tempos determinados, mas foram projetos a serem desenvolvidos em um tempo muito maior. Eu acho que é isso que eu chamaria de projeto de vida com a educação musical, porque não era somente apresentar um projeto para o CNPq ou para o departamento onde estava locada, mas, acima de tudo, ir caminhando ao longo desse tempo na busca por aprofundamentos (EN4, p. 8).

Os desafios epistemológicos enfrentados por Jusamara Souza demandaram encontros e confrontos na negociação do topoi biográfico. De acordo com Delory-Momberger (2012, p. 535), "ao confrontar relatos de si entre os topoi, constrói-se sentidos de si e formas próprias, tematizando, organizando e agindo nele como lugares de reconhecimento e chaves de interpretação da experiência". Jusamara recorre a um topos duplo: de um lado o topos socioindividual e do outro o topos coletivo. É na gestão do topoi 
biográfico que Jusamara Souza encontra-se como observadora de si a partir da recepção de sua obra.

Antes de se inserir na URFGS como professora concursada, em agosto de 1997, Jusamara conta que participou de um encontro de pesquisadores promovido pelo Programa de Pós-Graduação em Música da UFRGS, ocorrido na cidade de Porto Alegre, em outubro de 1996. As lembranças trazidas desse acontecimento mostram o modo como foi, nas palavras dela, "a recepção da obra":

Foi a primeira vez que apresentei o projeto submetido ao CNPq, que mais tarde seria publicado em forma de artigo, intitulado "O cotidiano como perspectiva para a aula de música" [Souza 1996b]. E, na apresentação desse texto, estavam presentes as professoras Alda Oliveira e Irene Tourinho [ambas fazem parte do grupo turma, dos seis primeiros doutores formados na área, no exterior]. Depois, me lembro de outros eventos, V Encontro Anual da Abem e VI Simpósio Paranaense de Educação Musical, realizados em 1996, em Londrina, nos quais discuti as contribuições da sociologia para a pesquisa em educação musical [Souza, 1996a]. Nessa apresentação, em uma mesa-redonda compartilhada com Lucy Green e Irene Tourinho, houve um esforço muito grande de minha parte para o entendimento de que o meu trabalho como pesquisadora não se tratava de sociologia, mas de uma sociologia da educação musical, um campo que, na época, ainda era pouco conhecido. Desde o início da minha carreira como pesquisadora, tive muita convicção das coisas que eu tinha vivido e estudado na Alemanha, tanto que eu pensava assim: Eu vou seguir e construir o meu caminho no campo da sociologia da educação musical (EN3, p. 17).

De fato, Jusamara sempre foi muito convicta de suas concepções epistemológicas. Se por um lado havia desafios, por outro havia uma persistência em manter-se construindo a sua história com a área. A esse respeito, uma das suas várias histórias construídas com a área foi pela epistemologia do texto, como é o caso das "Contribuições teóricas e metodológicas da sociologia para pesquisa em Educação Musical”, um texto publicado nos anais do V Encontro anual da Abem (Souza, 1996a). Dando sequência à pesquisa e à ação, um ano depois publica outro texto no VI Encontro anual da Abem e I Encontro Latino de Educação Musical da Isme: "O conceito de cotidiano como perspectiva para a pesquisa e ação em educação musical” (Souza, 1997).

Como descrito em seu memorial acadêmico, "esses têm sido os dois grandes eixos norteadores - Sociologia da Educação Musical e Epistemologia da Música/Educação Musical [de minhas atividades acadêmicas]", que, em suas palavras, "praticamente orientaram a minha produção bibliográfica e 
acadêmica, bem como as orientações de mestrado e doutorado ao longo desses 19 anos, como docente da UFRGS” (Souza, 2016, p. 22).

O objeto e a área de atuação do concurso para professor efetivo, que prestei em 1997, foram a Sociologia da Educação Musical. Desde 1996, com a publicação do texto "Contribuições teóricas e metodológicas da sociologia para a pesquisa em educação musical", nos Anais do 5० Encontro Anual da Abem e do 5o Simpósio Paranaense de Educação Musical [Souza, 1996], vinha me dedicando à análise das contribuições teóricas e metodológicas da sociologia para a pesquisa em educação musical. Compartilhava também da ideia de Beillerot sobre a necessidade de compreender que a "singularidade das situações [educativas] necessita de perspectivas filosóficas, históricas, sociológicas, psicológicas etc." [in Souza, 1996, p. 12]. Assim, já me via comprometida a discutir a posição epistemológica da área de educação musical, sempre com a preocupação da delimitação do campo da área como ciência ou área do conhecimento (Souza, 2016, p. 30).

Compreendemos melhor esses desafios epistemológicos quando nos colocamos diante de sua narrativa: "Sobre os textos escritos, tenho pensando que essa recepção e crítica é algo que não temos no Brasil, como se faz na Alemanha, por exemplo, onde os autores se referenciam uns aos outros, discutindo a obra. Acho que falta praticarmos mais isso na nossa área" (EN3, p. 17).

Essa é uma prática que pode ser exercida, também, com pesquisas dessa natureza - histórias de vida como obra -, o que significa, na teoria do texto de Paul Ricoeur, uma proposta da análise hermenêtica, uma vez que "o que deve ser interpretado, num texto, é uma proposição de mundo, de um mundo tal como posso habitá-lo para nele projetar um de meus possiveis mais próximos" (Ricoeur, 2008, p. 66).

Entendo com o autor que em toda obra tem-se o tempo refigurado. E é nesse encontro, entre obra e leitor, que existe um espaço privilegiado horizontes - para fazer encontrar neles a sua relação com o campo da educação musical. A prefiguração e a configuração se atualizam no ato da refiguração; assim, a razão da existência da obra vem à tona.

A mediação operada pelo texto conduz o leitor à apropriação de uma proposição de mundo, decorrente do encontro face a face com o mundo da obra. Pensando com Ricoeur (2008, p. 63), esta proposição não se encontra atrás do texto, como uma espécie de intenção oculta, mas diante dele, como aquilo que a obra desvenda, descobre, revela. Por conseguinte afirma o autor, "compreender é compreender-se diante do texto". A capacidade de compreender não repousa sobre o texto em si e sua capacidade finita de compreender, mas o sujeito, ao expor-se ao texto, recebe dele um si mais amplo, e sua compreensão se trata de "uma proposição de existência, 
respondendo, da maneira mais apropriada possivel, à proposição de mundo" (Ricoeur, 2008, p. 68). O sujeito passa, portanto, a ser constituído pelo mundo da obra e suas possibilidades (Souza, 2018a, p. 112).

\section{A CONSTRUÇÃO DE SUA HISTÓRIA AGUÇADA PELOS BIOGRAFEMAS}

Exercitei enxergar no texto "Contribuições teóricas e metodológicas da sociologia para pesquisa em educação musical" a pesquisadora Jusamara Souza como uma autora que se constitui pelo mundo da obra, observando "possibilidades que a perspectiva sociológica abre para o redirecionamento dos problemas contemporâneos da educação musical no Brasil" (Souza, 1996a, p. 13).

Também há um cuidado, por parte da autora, em aclarar ao leitor da área como foi feita a delimitação do campo, explicitando que, na Alemanha, há um debate sobre "a natureza da educação musical, sua especificidade face às ciências da educação, didática e contribuição destas ao fenômeno pedagógico musical no que diz respeito ao ensino e aprendizagem". A autora explica que, na década de 1970, Abel-Struht discutia a educação musical como "área autônoma e não autônoma", sendo a não autônoma composta de quatro possibilidades: aditiva, adaptativa, dupla participação, cooperação (Souza, 1996a, p. 14).

A autora vai mostrando ao seu leitor "como a problematização de uma questão epistemológica reveste o campo da educação musical, cuja natureza, objeto e método não se mostram suficientemente claros, uma vez que uma ciência se constituiu sabendo qual é o seu campo" (Souza, 1996a, p. 14). Nessa direção, abre-se uma questão central com Kraemer (1995, p. 146): Qual é o campo da educação musical? Possui um objeto claro?”. Ao que responde: "A educação musical se ocupa com relações entre seres humanos e músicas sob os aspectos de apropriação e transmissão". Em seguida, procura levar o leitor a compreensões da sua própria visão epistemológica que, na perspectiva da sociologia da educação musical, "ao seu campo de estudo fazem parte toda prática músico-educacional, dentro e fora das instituições, bem como todos os processos musicais de apropriação" (Souza, 1997, p. 14).

Adensando argumentos com Kaiser (1994), contemporâneo de Kraemer, a autora se posiciona: "Estando de acordo com isso, fica em aberto quais dimensões e funções o conhecimento músico-pedagógico pode abranger". E é com Kaiser que segue argumentando que o campo da educação musical é constituído

[...] nas relações entre indivíduos e músicas [ciências humanas e sociais], nos processos de apropriação e transmissão de música [elementos constitutivos da educação musical - músico-histórico; estético-musicais; sócio- 
musicais, etnomusicológicos; músico-psicológicos...], referindo-se ao efeito educacional da música no desenvolvimento da experiência (Souza, 1996a, p. 15).

Foi a partir da recepção dessa obra que comecei a pensar que, dentre os elementos constitutivos da educação musical, estão também os aspectos musicobiográficos. Isso significa dizer que esse texto de Jusamara Souza é denso e abre horizontes de possibilidades para pensar outros elementos constitutivos da educação musical, ou, nos termos da narradora/pesquisadora, "autores se referenciam uns aos outros discutindo a obra" e praticando isso de dentro da área.

Ao teorizar sobre a sua maneira de enxergar o fenômeno estudado, tento, como pesquisadora, nesse horizonte de abertura que o texto de Jusamara Souza me dá, fazer aproximações epistemológicas entre os campos da pesquisa (auto)biográfica e educação musical, "intentando exprimir com instrumentos terminológicos e nocionais termos que considero apropriados para a biografização do sujeito com a música Musicobiografização" (Abreu, 2017, p. 76).

Tais elucubrações só são possíveis no ir e vir dos processos analíticos de narrativas (auto)biográficas. Produzir uma metacompreensão à luz de análise das narrativas (auto)biográficas ajuda na constituição de uma educação musical que contemple, em seu escopo, as dimensões da compreensão cênica de teorias musicobiográficas integradas na relação entre biografia e educação musical, no caso, na relação entre a história de vida profissional de Jusamara Souza com a educação musical.

Como nos alerta a narradora/pesquisadora: "Se tu leres um texto ou outro apenas, talvez dificulte a compreensão do todo, mas o que tu estás fazendo é ler o conjunto de uma obra, assim tu consegues ler na obra mais da pessoa no seu próprio texto" (EN3, p. 21). Esse é, portanto, o horizonte de possibilidades que poderá ser preenchivel mediante a obra de uma autora como Jusamara Souza, que conta não como se faz, mas como fez para fertilizar teorias e metodologias em educação musical. Para ela, "o autor é um tradutor de ideias, tradutor do mundo, do jeito como vejo a área e busco traduzir nos textos" (EN3, p. 21).

Como autora, busca erguer no texto uma proposição para que se discuta os confrontos e encontros da educação musical com a Sociologia (Berger, 1991 apud Souza, 1996a, p. 16), considerando o porquê da Sociologia se tornar importante para a pesquisa em educação musical. Discorrendo sobre o mundo da vida, faz referência à sua atuação em um projeto escolar desenvolvido com crianças imigrantes, refugiados que iam para a Alemanha no período após a guerra da Bósnia (abril de 1992 a dezembro de 1995), projeto este que abrangia não só a música, mas também visava à Sociologia, à vida cotidiana das famílias desses alunos migrados de outros países. 
Como pesquisadora da área, busca, nesse entrelaçamento da educação musical com outras áreas do conhecimento - Música, Sociologia e Educação -, aproximar-se dos estudos de Selma Pimenta (1996a, 1996b), que constrói o objeto da Pedagogia com teorias explicativas para, então, provocar pesquisadores da educação musical a pensarem na "questão que teremos de nos debater, trazendo originalidade e especificidade de um projeto de pesquisa em educação musical” (Souza 1996a, p. 33). Com essa pesquisa, realizada há mais de vinte anos, concluiu que "os resultados até agora obtidos apontam, sobretudo, para mudanças na natureza das relações sócio-pedagógicas propostas para a sala de aula que se deslocam de um modelo autoritário para um modelo democrático e pluralista de ensino" (Souza, 1996a, p. 35).

Jusamara Souza segue com teorias explicativas, construindo, no Brasil, "O conceito de cotidiano como perspectiva para a pesquisa e ação em educação musical" (Souza, 1996a, 1997). Isso remete às palavras de DeloryMomberger (2014, p. 59), de que "só posso (re)construir o mundo da vida que ouço ou leio, relacionando esse mundo com os meus próprios construtos biográficos" e compreendendo-o nas relações de ressonância e inteligibilidade com a minha própria experiência. A própria experiência, no caso, advém de práticas e, principalmente, de leituras de teóricos como aqueles referenciados em Souza (1997): "Berger, Heller, Husserl, Lefebvre, Pimenta e a própria Souza (1996a)". Diante disso, trago excertos de DeloryMomberger (2014) para aclarar esse pensamento:

Os teóricos da leitura desenvolveram a ideia de que a recepção de um texto inscreve-se sempre num horizonte de expectativa, o qual é condicionado pelo estado da bioteca do leitor, ou seja, pelo conjunto de textos lidos anteriormente, pelas experiências de leitura e pelos "saberes" múltiplos que permitiram construir. Horizonte de expectativa e bioteca condicionam a construção de sentido do novo texto proposto à leitura (Delory-Momberger, 2014, p. 58).

Ao se referir a essa teoria da recepção literária, de uma bioteca, DeloryMomberger entende que isso faz parte de um "conjunto das experiências e dos saberes biográficos, ou biografemas, do receptor", da mesma forma que, "no ato da leitura, a construção do sentido é orientada e finalizada pelo horizonte de expectativa do leitor [...] na sua relação com os interesses de conhecimento que esse horizonte lhe oferece" (Delory-Momberger, 2014, p. 59). Dito de outro modo pela autora,

Eu me aposso prioritariamente dos biografemas (pessoais, sociais, históricos, culturais, imaginários) que podem ser integrados à minha própria construção biográfica, na medida em que respondem, aqui e agora, ao meu próprio mundo da vida (Delory-Momberger, 2014, p. 58-59). 
É com essa visão que ampliamos compreensões de que a construção da história de vida profissional de Jusamara com a educação musical, frente aos seus desafios epistemológicos, é aguçada pelos biografemas. Logo, "o objeto que construo está estreitamente ligado ao sistema de interpretação constituído por minha bioteca pessoal e pela rede de biografemas que se encontram à minha disposição" (Delory-Momberger, 2014, p. 59).

Para respaldar a prática, Jusamara Souza apresenta em seu texto parte da sua bioteca, com autores de "correntes fenomenológicas e conceitos da Filosofia e da Sociologia compreensiva" (Souza, 1997, p. 39). Com Harold Garfinkel, chama a atenção do leitor para aquilo que se propõe a desenvolver com pesquisas e ações em educação musical, dando atenção para "as coisas que são habitualmente vistas, mas não notadas" (Souza, 1997, p. 39), com vistas a trazer uma problemática para a área de educação musical com "questões fundamentais vinculadas à prática músico-cultural e ao currículo sob a ótica da sociologia da educação" (Souza, 1997, p. 39).

Nessa direção, afirma que a experiência estética cotidiana na escola "não é predominantemente impregnada pela aula, mas pela influência da família, do ambiente sonoro e da mídia, sobretudo no que se refere à sua função e efeitos" (Souza, 1997, p. 39). A autora chama a atenção dos leitores para as complexidades que envolvem o campo, uma vez que "tomar o cotidiano como referencial teórico é um empreendimento complexo. Existem problemas metodológicos no tratamento do tema que merecem ainda discussões mais aprofundadas", apontando a primeira delas como a dúvida se a "Filosofia ou a Sociologia estaria, de fato, oferecendo um novo instrumento metodológico para a interpretação da realidade, ou se não passaria de um modismo" (Souza, 1997, p. 40). Acredita que "a importância desse trabalho revela-se, sobretudo, no paradigma da experiência musical como uma experiência social, mostrando, assim, que também a educação musical não pode se valer no caráter a-histórico [que não participa da história]" (Souza, 1996a, p. 40).

É fato que a educação musical brasileira vem se valendo de um caráter histórico. Dez anos depois dessa publicação, ao prefaciar o livro organizado por Alda Oliveira, Educação Musical no Brasil (Souza, 2007), Jusamara Souza inicia o texto com uma questão: "Como se narra uma história da educação musical? [...] A história da educação musical é vista por meio de outras histórias, como a da educação, ou buscando a história da educação musical na própria história"; isto é, partindo de trabalhos tidos como referências nessas áreas. Sobre as muitas histórias de muitos espaços de educação musical, Jusamara Souza enxerga um coletivo da área: "Autores reunidos neste livro, que nunca estiveram juntos em um simpósio ou evento. Mas, no livro, se encontram e falam uns com os outros". Juntandose a eles, enxergamos no texto a sua visão epistemológica de que "há um entendimento comum de que os espaços onde nos formamos são múltiplos: nos espetáculos, nas ruas, nas escolas, nas orquestras, em projetos sociais, 
em grupos vocais e instrumentais e muitos outros". De modo que, nos dez anos que se passaram, reconhece, na recepção da leitura de outros autores, que no Brasil “a educação musical está ampliada” (Souza, 2007, p. 6).

Como escrevi em alguns textos, uma área não se faz só com pessoas, mas se faz também com os materiais produzidos por estas pessoas, com os tipos de materiais, de crenças e valores que vamos passando por meio desses materiais, isso é forte no coletivo de uma área (EN3, p. 5).

Compreendo, com as ideias de Souza (1997), na abertura de horizontes, que o seu texto nos dá "o paradigma da experiência musical como uma experiência social” (Souza, 1997, p. 39) - e, nesse paradigma, se encontra o sujeito biográfico como aquele capaz de religar o sujeito histórico, empírico e epistêmico. É com esse sujeito que ocorre a valoração do caráter histórico de um campo investigativo formado por um sistema contextualizado por diversas biotecas e biografemas, inscrevendo pesquisadores num quadro de referências partilhadas, tornando disponivel a soma de saberes experienciais no domínio biográfico e, para usar nossos termos, no domínio musicobiográfico.

\section{CONSIDERAÇÕES FINAIS}

Ao aprender com Paul Ricoeur que compreender é compreender-se diante do texto, vejo-me diante da pesquisa realizada durante o pósdoutorado com a tarefa que não se encerra, ao contrário, ergue-se do horizonte de possibilidades o percurso do reconhecimento de tamanha responsabilidade na formação de professores e pesquisadores no campo da educação musical. Na aventura desse diálogo (auto)biográfico, na construção de uma história de vida, a nossa história com a área também foi sendo refigurada.

A noção epistemológica de reconhecimento, para Ricoeur (2006), é de identificação, de capacidade antropológica de si mesmo como um outro, chegando à noção de política. No percurso do reconhecimento está dado o potencial do agente transformador. Esse potencial é dado pela memória e pela promessa, exigindo esforço por existir e desejo de uma vida realizada, no meu caso, com campos investigativos da pesquisa (auto)biográfica e da educação musical. O sentido de uma vida científica carrega em si a abertura de um compromisso com "instituições justas", como assinala Paul Ricoeur. O justo tem relação com a reciprocidade mútua, isto é, aquele que dá reconhece quem o recebe, significando que viver em comunidades "científicas" institucionalizadas exige o contínuo reconhecimento do outrem e de si mesmo com um outro.

Reconhecer-se como um outro dentro de uma área de conhecimento da qual faz parte pode fornecer condições de querer construir a sua história de vida nas "significações do narrar de si/narrar do outro no diálogo 
(auto)biográfico de uma aventura epistemo-empírica” (Abrahão, 2018, p. 68). É no reconhecimento mútuo de nossas histórias de vida implicadas com um campo investigativo que os horizontes de responsabilidades seguem no seu percurso.

\section{REFERENCIAS}

ABRAHÃO, Maria Helena Menna Barreto. A aventura do diálogo (auto)biográfico: narrativa de si/narrativa do outro como construção epistemo-empírica. In: ABRAHÃO, Maria Helena Menna Barreto (Org.). A Nova Aventura (Auto)Biográfica - Tomo II. Porto Alegre: EdiPUCRS, 2018. p. $43,68$.

ABRAHÃO, Maria Helena M. B. Destacados educadores brasileiros: suas histórias, nossa história. Porto Alegre: EdiPUCRS, 2016.

ABREU, Delmary Vasconcelos. A construção da Educação musical no Distrito Federal: histórias de vida na perspectiva epistêmico metodológica. In: MORAES, D. Z.; CRYSTIVA, A.; MARTINS, R. (Orgs.). Narrativas digitais, história, literatura e artes: atos de biogr@far. Curitiba: Editora CRV, 2018. p. 265-285

. O FAEM como espaço de formação em educação musical: uma investigação-formação a partir de memoriais de mestrandos da UnB. Revista da Abem, v. 25, n. 38, p. 89-104, jan./jun. 2017.

. Levino Ferreira de Alcântara: a gênese da educação musical no Distrito Federal. In: ABRAHÃO, M. H. M. B. (Org.). Destacados educadores brasileiros: suas histórias, nossa história. Porto Alegre: EdiPUCRS, 2016. p. 119-146.

ARROYO, Margarete. Educação Musical na Contemporaneidade. In: SEMINÁRIO NACIONAL DE PESQUISA EM MÚSICA DA UFG (SENPEM), 2., 2002, Goiânia. Anais [...]. Goiânia: UFG, 2002. p. 18-29.

BOLÍVAR, Antonio; DOMINGO, Jesús; FERNÁNDEZ, Manuel. La investigación biográfico-narrativa en educación enfoque y metodologia. [S. 1.]: E. Muralla, 2001.

DELORY-MOMBERGER, Christine. Biografia e Educação: figuras do Indivíduo Projeto. Tradução e Revisão Científica de Maria da Conceição Passeggi, João Gomes da Silva Neto, Luis Passeggi. 2. ed. Natal: EdUFRN, 2014.

Abordagens metodológicas na pesquisa biográfica. Revista Brasileira de Educação, v. 17, n. 51, p. 523-740, set./dez. 2012.

Formação e socialização: os ateliês biográficos de projeto. Educação e Pesquisa, São Paulo, v. 32, n. 2, p. 359-371, maio/ago. 2006. 
KRAEMER, Rudolf-Dieter. Dimensões e funções do conhecimento pedagógico-musical. Tradução Jusamara Souza. Revista em Pauta, v. 11, n. 16/17, p. 48-73, 2000.

OLIVEIRA, Alda. Relatório da associação brasileira de educação musical gestão das primeiras diretorias - 1991-1995. Revista da Abem, v. 2, nov. 2014. Disponivel em:

http:/ / www.abemeducacaomusical.com.br/revistas/revistaabem/index.php /revistaabem/article/view/505. Acesso em: 8 may 2018.

PASSEGGI, Maria da C.; SOUZA, Elizeu C. O Movimento (auto)biográfico no Brasil: esboço de suas configurações no campo educacional. Investigação Qualitativa, v. 2, n. 1 p. 6-26, 2017.

PASSEGGI, Maria da Conceição; ABRAHÃO Maria Helena Menna Barreto; DELORY-MOMBERGER, Christine. Reabrir o passado, inventar o devir: a inenarrável condição biográfica do ser. In: PASSEGGI, M. C.; ABRAHÃO, M. H. M. B. (Orgs.). Dimensões epistemológicas e metodológicas da pesquisa (auto)biográfica: Tomo II. Natal: EdUFRN; Porto Alegre: EdiPUCRS; Salvador: EdUNEB, 2012. p. 29-58.

PIMENTA, Selma. Para uma ressignificação da didática. Ciências da Educação, Pedagogia e Didática: uma revisão conceitual uma síntese provisória. In: ENDIPE, 7., 1996, Florianópolis. Anais [...]. Florianópolis, 1996a. Mimeo.

(Org.). Pedagogia Ciência e Educação? São Paulo: Cortez, 1996b.

PINEAU, Gaston. A tríplice aventura (auto)biográfica: a expressão, a socialização e a formação. In: ABRAHÃO, Maria Helena Menna Barreto; PASSEGGI, Maria da Conceição (Orgs.). Dimensões epistemológicas e metodológicas da pesquisa (auto)biográfica: Tomo I. Natal: EdUFRN; Porto Alegre: EdiPURCS; Salvador: EsUNEB, 2012. p. 139-158. Coleção Pesquisa (Auto)biográfica: Temas Transversais.

RICOEUR, Paul. O si-mesmo como outro. Tradução Ivone C. Benedetti. 1· ed. São Paulo: WMF Martins Fontes, 2014.

. Tempo e Narrativa: o tempo narrado. Tomo 3. São Paulo: WMF Martins Fontes, 2010.

Hermenêutica e Ideologias. Petrópolis, RJ: Vozes, 2008.

Percurso do reconhecimento. São Paulo: Loyola, 2006.

SARAMAGO, José. Biografias. O caderno de Saramago, 22 set. 2008.

Disponivel em: http://caderno.josesaramago.org. Acesso em: 12 out. 2017.

SOUZA, Jusamara. Entrevista narrativa. A história de vida de Jusamara Souza com a educação musical: desafios epistemológicos. Projeto de pesquisa (Pós-doutorado em Educação) - UFPel, Pelotas, 2018a. 
. Relatório. In: ENCONTRO PERMANENTE DO FÓRUM DE PESQUISA EM EDUCAÇÃO MUSICAL, 5., 2018, Brasília. ABEM, Brasília, 2018b.

Memorial acadêmico. Porto Alegre: Universidade Federal do Rio Grande do Sul, 2016.

. Sobre as várias histórias da educação musical no Brasil. Revista da Abem, Londrina, v. 22, n. 33, p. 109-120, jul./dez. 2014.

. História da educação musical no Brasil: à guisa de um prefácio. In: OLIVEIRA, Alda; CAJAZEIRA, Regina (Org.). Educação musical no Brasil. Salvador: P\&A, 2007.

- O conceito de cotidiano como perspectiva para a pesquisa e a ação em educação musical. In: ENCONTRO LATINO-AMERICANO DE EDUCAÇÃO MUSICAL, 1.; ENCONTRO ANUAL DA ABEM, 6., 1997, Salvador. Anais [...]. Salvador: Isme, Abem, 1997. p. 38-43.

. Contribuições teóricas e metodológicas da Sociologia para a pesquisa em Educação Musical. In: ENCONTRO ANUAL DA ABEM; SIMPÓSIO PARANAENSE DE EDUCAÇÃO MUSICAL, 5., 1996, Londrina. Anais [...]. Londrina, 1996a. p. 11-39.

. O cotidiano como perspectiva para a aula de música. Fundamentos da Educação Musical, Porto Alegre, v. 3, p. 61-74, $1996 \mathrm{~b}$.

Repensando a pesquisa em educação musical. In: ENCONTRO ANUAL DA ANPPOM, 9., 1996, Rio de Janeiro. Anais [...]. Rio de Janeiro: ANPPOM, 1996c. p. 80-86.

Delmary Vasconcelos de Abreu é professora nos cursos de Licenciatura em Música presencial e a distância no Departamento de Música da UnB. Atua nas disciplinas relacionadas à área de educação musical. https://orcid.org/0000-0001-5787-5703 